Journal of Teacher Education for Sustainability,

vol. 12, no. 2, pp. 97-109

\title{
EFFECTING CHANGE THROUGH LEARNING NETWORKS: THE EXPERIENCE OF THE UK TEACHER EDUCATION NETWORK FOR EDUCATION FOR SUSTAINABLE DEVELOPMENT AND GLOBAL CITIZENSHIP
}

\author{
Sally Inman, Sophie Mackay, Maggie Rogers and Ros Wade \\ London South Bank University, Great Britain
}

\begin{abstract}
The paper discusses and evaluates the experience of the UK Teacher Education Network for education for sustainable development and global citizenship as a community of practice dedicated to embedding education for sustainable development and global citizenship in teacher education in the UK. The article sets out the global and UK policy context for education for sustainable development and global citizenship and outlines the differing government support and guidance for education for sustainable development and global citizenship in teacher education across the four nations of the UK. The paper concludes by arguing that the Network is successful in the first of the aims as there is now a vibrant UK wide teacher education community of practice in education for sustainable development and global citizenship whereby radical practice can be explored, questioned and shared. However, the rapidly changing government policy context for education particularly in England makes it difficult to predict how effectively the Network can affect policy change and/or long lasting change in course content so as to embed education for sustainable development and global citizenship in teacher education across the UK. The authors suggest that the Network will need to work alongside new and existing alliances to try to convince policy makers of the critical need to ensure that new teachers are equipped to introduce education for sustainable development and global citizenship in schools.
\end{abstract}

Key words: education for sustainable development, global citizenship, community of practice, teacher education

\section{Introduction}

Although there have been some considerable achievements over the last 20 years with regard to poverty eradication, it is clear that many of the Millennium Development Goals (MDGs) are unlikely to be fulfilled (UN MDG Report 2010). MDG 7 on environmental conservation has hardly been addressed and there has been very little evidence that concerns about poverty eradication and environmental degradation are being addressed 
together or being integrated into policy and planning processes. In Cancun, in December 2010, the nations of the world signed up to some pledges to keep global temperatures to no more than a rise of 2 degrees $C$. Even if this were to be achieved the effects of such a rise could be catastrophic for fragile areas of the globe and would not prevent a dramatic change in climactic conditions worldwide (Lynas, 2007). These issues present a great challenge to teachers, since the young people of tomorrow will need a different range of skills, knowledge and understanding in order to survive.

There is a long history of environmental and development education in the UK, spanning many decades. This has been greatly influenced by non-government organizations (NGOs) like World Wide Fund for Nature and Oxfam whose education departments have developed innovative educational resources and training courses. After the Earth Summit in 1992 endorsed the importance of education for sustainable development (ESD), it was clear that development needs and environmental concerns needed to be considered within this overarching framework, rather than separately. Hence, for example, WWF, Oxfam and a consortium of NGOs came together in 1993 to develop a brand new master's course in environmental and development education. This resulted in a unique collaboration between environmental and development organizations and the academy through London South Bank University (www.lsbu.ac.uk/efs). This collaboration has developed further through the UK Teacher Education Network. In order to respect the separate histories of environmental education and development education, it was decided to keep these identities through the name of the network, using the terms 'global citizenship' (GC) and 'education for sustainable development' (ESD). The two terms can be thought of as two sides of the same coin, with the notion of agency provided by 'global citizenship' and 'education for sustainable development' providing the context and processes. By working together in a collaborative way, we hope to build a movement which integrates issues of social and environmental justice, poverty eradication and ecological conservation, social and biological diversity.

\section{The UK context}

In many countries, there is now government policy in place for education for sustainable development, though not global citizenship, in all areas of the formal education sector, from schools to higher education. In addition, national legal requirements on sustainable development in relation to other sectors, such as the built environment, have created space and demand for training at a range of levels. At the international level, education was further endorsed at the second World Summit on Sustainable Development (WSSD), which took place in Johannesburg in 2002. This also attempted to make links between education for sustainable education and education for all (EFA - basic education as a requirement for the achievement of the Millennium goals on poverty reduction). The government of Japan also led the successful lobbying for education to be given the status of a UN Decade from 2005 to 2014. Education is now viewed as a prime lever for social change, described by UNESCO in the implementation plan for the Decade in the following way: "It [ESD] 
means education that enables people to foresee, face up to and solve the problems that threaten life on our planet" (UNESCO, 2005, p. 5).

In the UK, environmental and development NGOs were initially responsible for taking forward the $\mathrm{ESD} / \mathrm{GC}$ agenda though, in the last 5 years, there has been increasing support from the Labour government, for example, in relation to the school curriculum and the Sustainable Schools networks. In addition, the Learning and Skills sector has developed policy on sustainability as has the Higher Education sector (UK National Commission for UNESCO 2010). Specific approaches have also had results, such as the work of Oxfam, RSPB and WWF in Wales to incorporate ESD/GC in educational requirements. The Welsh Assembly further endorsed this with a dedicated staff member to oversee the incorporation of ESD and GC in the school curriculum and also within teacher education. A number of UK Regional Centres of Expertise have also been accredited by the United Nations University in order to take forward regional agendas in sustainability.

However, since the May 2010 General Election a new government coalition of Conservatives and Liberal Democrats has started to change the political landscape. Since May, the support for Sustainable Schools has been cut, along with the abolition of the Sustainable Development Commission (a quasi-independent body) which provided advice and critique on the government's policies in relation to sustainable development. The global learning programme of the Department for International Development which funded much of the regional formal sector work in $\mathrm{ESD} / \mathrm{GC}$ was also cut at a stroke, leaving many projects unfinished. Much of this has been justified by the need for government cuts in the face of the UK budget deficit caused by the bail out of UK banks. However, the choice of what to cut is inevitably a political decision, and it is interesting, though depressing, to note that one of the first targets for cuts has been work in ESD/GC. The challenge now is to continue to move forward in changing times and to find creative ways to develop ESD/GC across the formal education sector.

\section{Teacher education in the UK: ESD and global citizenship}

Institutions of Teacher Education fulfil vital roles in the global education community; they have the potential to bring changes within education systems that will shape the knowledge and skills of future generations. Often, education is described as the great hope for creating a sustainable future. Teacher education institutions serve as key change agents in transforming education and society so such a future is possible. (UN, 2005, p. 11)

What contribution can teacher educators make to the development of teachers as 'change agents' with the knowledge, skills and values to promote ESD in ways that enables young people to make a difference and bring about a better world? Within each of the four UK countries, teacher educators have worked to embed $\mathrm{ESD} / \mathrm{GC}$ within the teacher educator curriculum with greater or lesser success. 


\section{England}

In England, as elsewhere, ESD/GC in teacher education has often relied on the commitment of individuals and groups, and the curriculum provision for ESD/GC in initial teacher education (ITE) has therefore been patchy across the country. The development of a more coherent provision has been hindered by the fact that successive revisions of the Training Standards for ITE (Training and Development Agency, 2007), which govern the ITE curriculum in England have not made any explicit reference to ESD/GC. The current Standards make no explicit mention of the need for new teachers to develop knowledge, skills and attitudes in relation to these critical areas of knowledge, skills and values. There is little to encourage those involved in the training of new teachers to provide education for sustainable development and global citizenship a central place in the training programme. However, a group of ITE tutors committed to embedding ESD and global citizenship within ITE have worked together to develop a set of contextual questions which enable tutors and students to think about the global dimension of the Professional Standards (a group of ITE tutors and NGOs committed to embedding ESD/GC within ITE have worked together to develop). At the time of writing, it is not clear how the Standards for ITE might be revised under the coalition government but what seems clear is that there will be no explicit mention of the need for new teachers to receive training in $\mathrm{ESD} / \mathrm{GC}$. The recent government White Paper on education makes no mention of ESD/GC but emphasises, instead, the importance of new teachers receiving more training in some areas, such as early reading and mathematics, special educational needs and classroom management (DfE, 2010).

\section{Wales}

In contrast, the Standards for new teachers in Wales make specific references to education for sustainable development and global citizenship so as to enable new teachers to develop the knowledge, skills and attitudes to promote the ESD/Global Citizenship (GC) now embedded in the Welsh curriculum (Welsh Assembly, 2006). In the section on knowledge and understanding, there is a requirement that all new teachers are familiar with the most recent national guidance on the promotion of Education for Sustainable Development and Global Citizenship. In the section on Teaching and class management, it is possible to find the statement that student teachers should be trained to

take appropriate opportunities to promote and teach education for sustainable development and global citizenship in all relevant aspects of their teaching (Welsh Assembly, 2006, p. 24).

Curriculum guidance has also been developed in Wales around ESD/GC for teachers, teacher educators and trainee teachers to help them to embed this work within the curriculum and pedagogy. (Welsh Assembly, 2006, 2008; Bennell, 2008) 


\section{Scotland}

The Teacher Education Standards for Scotland include explicit references to the requirement that new teachers know about and are committed to ESD/GC. For instance, in Standard 3.3 concerned with the need for new teachers to demonstrate that they value, respect and show commitment to the communities in which they work we find the requirement that new teachers will

know about environmental issues and be able to contribute to education for sustainable development;

know about the principles of education for citizenship and be willing to encourage pupils to be active, critical and responsible citizens within a local, national, international and global context. (GTCS, 2006, p. 9)

The International Development Education Association of Scotland (IDEAS) is a strong network of organizations that support ESD/GC within the curriculum. IDEAS has a strong presence in teacher education and has been influential in developing ESD/GC within the teacher education curriculum in Scotland (Wisely, Barr, Britton, \& King, 2010). The arrangements for teacher education in Scotland are currently under review, it will be interesting to see how provision for ESD/GC might be altered in any potential revision of the Standards.

\section{Northern Ireland}

The Department for Employment and Learning (DEL) and the Department of Education (DE) have undertaken a joint review of teacher education. The purpose of the review was to ensure that the profession is best placed to cope with the changes facing the education sector in the coming years.

The Northern Ireland teacher competences as set out by the General Teaching Council for Northern Ireland (2006) in Teaching: the Reflective Profession (GTCNI) do not include any specific references to ESD/GC (GTCNI, 2006). As in England, it has been the inclusion of ESD/GC within the school curriculum that has helped to drive the need for ESD/GC within teacher education (Mc Quaid, 2008). However, in setting out the competences the GTCNI make a strong case for celebrating the complexity of teaching and rejects a reductionist approach to teacher education. It describes teachers as educators and moral agents who are both reflective and activist and adopts the approach of Dalmau and Gudjonsdottir (2002) in specifying the diverse roles of teachers as encompassing roles that embody elements such as critical reflection, research and change making. Thus, whilst there are no specific competences to do with $\mathrm{ESD} / \mathrm{GC}$ the whole approach to teacher education is one that stresses the need for new teachers to be creative, reflective change makers 'competencies' that sit well with ESD/GC.

Thus, in the four UK nations there are differences in the ways in which ESD/GC features in official documentation and guidance for teacher education. Wales and Scotland 
have explicit standards and guidance; Northern Ireland and England make no explicit reference to ESD/GC though the whole approach within Northern Ireland resonates well with the aims and philosophy of ESD/GC. Of the four nations England is clearly the weakest with respect to government support and guidance for $\mathrm{ESD} / \mathrm{GC}$ within teacher education.

\section{The UK ESD/GC Teacher Education Network}

The UK network evolved from collaboration with World Wide Fund for Nature UK, Oxfam and teacher educators. In the UK, environmental and development NGOs have been in the forefront of promoting and supporting ESD. The idea for a network was discussed at a WWF organized seminar for teacher educators where the patchiness of ESD/GC provision within teacher education across the UK was explored and, in 2007, the Centre for Cross Curricular Initiatives (CCCI) at London South Bank University (LSBU) launched the UK Teacher Education Network for ESD/GC with funding from ESCalate, the Higher Education Academy's subject centre for Education, WWF-UK and the Training and Development Agency for Schools (TDA). We later received funding from Oxfam Education. The management of the network is undertaken by CCCI and this is overseen by a steering group comprising key players from the four UK countries.

The Network has representation from nearly all UK TE providers, including School Centred Initial Teacher Training institutions (SCITTs) and further education, NGOs, subject associations, national educational bodies, including the University council for the Education of Teachers (UCET), the TDA, ESCalate and the Development Education association (DEA). We currently have a membership of over 70 teacher education providers (many with four or five individual members), 42 NGOs and 10 national educational bodies.

In 2007, at the launch of the Network in 2007, we agreed on two central aims:

1. to develop a UK wide community of practice in ESD/GC and teacher education, through which good practice can be shared and disseminated and further development can be initiated and developed across the sector;

2. in the longer term, to contribute to embedding ESD/GC in UK TE institutions in relation to ethos, curriculum content, learning and teaching and assessment.

These aims have been regularly revisited over the past 3 years but remain the central aims of the network. We have developed a range of strategies to meet these aims. These include the development of regional networks and groups across the UK; UK conferences; the use of the website to disseminate events, research, network conference proceedings, meetings with educational bodies in England including the TDA and the Department for Children, Schools and Families (now Department of Education). We have made links with international networks engaged in the same area of work. Since we began in 2007, we have been committed to developing and embedding a radical practice underpinned by theory and to develop a genuine community of practice for those committed to ESD/GC. Whilst we are 
still on a long and sometimes difficult journey to meet these challenges, we are confident that we are on the right path.

\section{The UK Network as a community of practice}

Wenger (2006) describes communities of practice as groups of people who share a concern or a passion for something they do and learn how to do it better as they interact regularly.

The UK ED/GC ITE Network functions as a community of practice in a number of ways locally (within institutions), regionally, nationally and internationally. At a regional level meetings take place between tutors from ITE providers in a particular region to share practice around integrating $\mathrm{ESD} / \mathrm{GC}$ into Initial Teacher Education programmes. The sharing of practice has resulted in innovation and change at some individual institutions. This course based learning impacts the PGCE students at these institutions and the pupils they teach while on teaching practice and potentially throughout their teaching career.

For example, two members of the London Regional group, University of East London (UEL) and the Open University have integrated ESD/GC concepts into their secondary PGCE courses as a result of participation in the group.

UEL snapshot:

Secondary PGCE students were required to work collaboratively on a global citizenship project. Across the different curriculum subject areas, they were training in. At an introductory session, students were allocated to a virtual school. Each virtual school picked one of four themes ('Children's Rights and Responsibilities', 'Conflict Resolution', 'Sustainability' and 'Identities'). These themes informed the cross curricular work on the virtual schools for the year. Each virtual school worked collaboratively between December 2009 and February 2010. During February, a whole day was allocated for all virtual schools to work together in preparation for the presentation of collaborative projects held in June 2010.

UEL are using the analysis of the evaluations of this project to inform the development of the project as it moves into its third year. During the course of the academic year 2010/2011, they will be looking at the way in which global citizenship is connected with the developments around the London 2012 Games and its legacy. The project will be enhanced in this iteration by the integration of an expectation that the PGCE students will develop and deliver a session around the contextualised global dimension with pupils from partner schools.

Projects like the one set up at the University of East London were made possible as a result of a small amount of funding provided by the London Group via the Department for International Development's (DfID) Enabling Effective Support strategy, which in 2009 was renamed the Global Learning Strategy.

Regular meetings of regional groups provide opportunities for learning from one another, reflecting on and improving existing practice and support of developing new ideas. For instance, in 2011, a number of regional seminars funded and supported by Escalate are 
taking place to facilitate the dissemination of work done by ITE institutions around the UK to schools and other ITE providers in the region who may not be aware of work taking place on integrating ESD/GC into ITE.

The work that takes place within the regions of the UK feeds into the steering group, which is largely comprised of representatives from across the region of the UK, so there is a sharing of the practice that is taking place at institutions with in the regions. This sharing at the steering group level then feeds back into regional activities at individual institutions.

The activities of the network are shared internationally though papers delivered at conferences and through articles in journals. The UK Network is a member of the UNESCO International Network on Reorienting Teacher Training to address Sustainability, and this provides another means of disseminating the work carried out by teacher education providers. Two members of the UK Network delivered a paper on the way in the UK Network operates as learning community of practice at the 2008 UNESCO Teacher Education conference at Anatolian University, Eskisehir in Turkey.

The multilayered nature of the UK Network means that there is a two way flow of information between the different communities of practices (regional, national and international) of which the Network is comprised, as in Figure 1 shown below.

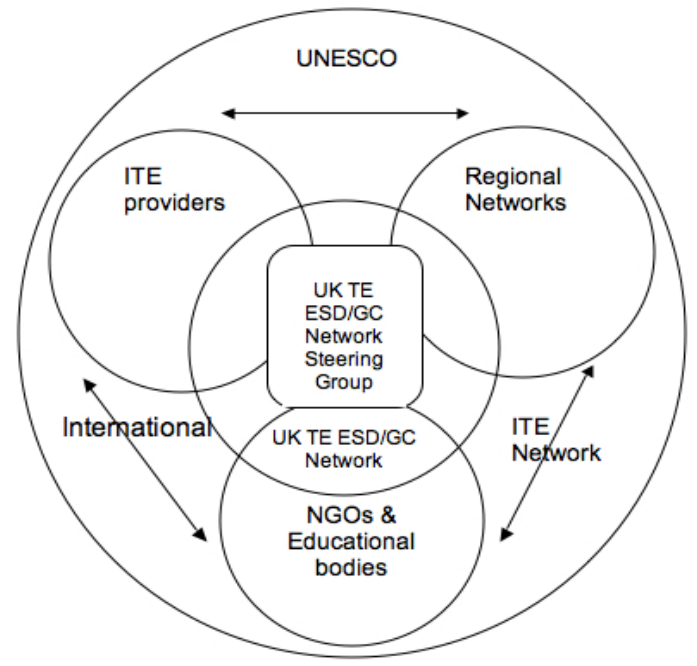

Figure 1. Multilayered nature of the UK Network and the relation of its groups to the international network

Wenger (2006) notes that communities of practice operate along three dimensions in the field of education:

1. Internally: How to organize educational experiences that ground learning in practice through participation in communities around subject matters? This relates to the learning around ESD/GC that happens within an ITE institution.

2. Externally: How to connect the experience of students to actual practice through peripheral forms of participation in broader communities beyond the 
walls of the school? This relates to the sharing of practice between institutions regionally and nationally through the network.

3. Over the lifetime of students: How to serve the lifelong learning needs of students by organising communities of practice focused on topics of continuing interest to students beyond the initial schooling period? This relates to the learning of beginning teacher beyond their initial training and how they might continue to develop their knowledge and understanding on $\mathrm{ESD} / \mathrm{GC}$ as the progress in their teaching careers.

All three points on the list above have relevance to the work of the UK Network as a community of practice and the different levels at which it operates.

The development of the UK TE Network has been against a backdrop of changing and differing policies driving $\mathrm{ESD} / \mathrm{GC}$ in the four UK countries, as outlined earlier. These differing policies and approaches were outlined at the first UK TE Network conference in 2008 and have informed the activities of the Network through representation from the four countries at Steering Group meetings. The Network has liaised with existing regional networks across the UK and has worked to establish or revive regional networks where appropriate. As the Network works across the four nations and different regions within them, it is important that we ensure that we continue to learn from the best practice and strategic thinking from the different nations and regions.

We are convinced from the feedback received from a range of sources that the Network has raised the profile of $\mathrm{ESD} / \mathrm{GC}$ through the website, conferences, regional networks and events and through talking about the network aims and activities at educational and policy conferences and seminars across the four nations and internationally. In October 2009, the Steering Group identified the need to do more to raise the profile of ESD/GC within every ITE institution across UK. We decided to mount a survey of ESD/GC provision within teacher education across the UK to find out the 'state of play' across each region and nation and to develop further strategies for embedding provision across teacher education. The data from this survey is being analysed at the time of writing and the results will be published early in 2011. Early analysis would suggest that, while many ITE providers are attempting to embed ESD/GC within their training programmes and are making good use of support and resources from NGOs and other agencies, more needs to be done to help institutions share practice and link with each other, especially during times of enormous changes. The Network will take on this challenge.

Pivotal to the development of a learning community of practice is the Network Steering Group. The group comprises representatives from teacher education in England, Scotland, Northern Ireland, Wales and regions within England. It has also representation from NGOs, national educational bodies, such as ESCalate, the University Council for the Education of Teachers, the Development Education Association, all educational sectors and from the Training and Development Agency that regulates teacher education in England. Thus, the group includes a very important range of expertise and experience in relation to research, policy and practice. It is this group that decides Network policy and activities. The management team at CCCI LSBU is supported by and accountable to this steering group, 
and this is an important feature of the way that the network operates, as it is seen to be inclusive, democratic and responsive to the needs of members.

\section{Annual conferences}

A major challenge for the Network is to ensure that we promote and share practice that is underpinned by theory and embraces critical thinking. The annual conference has been a useful vehicle through which to do this. Themes for each of the ESD/GC network conferences have engaged with current issues with an underlying focus on critical reflection to ensure that we challenge assumptions with respect to policy, research and practice and ask questions about the effectiveness and impact of the ESD/GC research and projects. For the inaugural conference in 2008, it was decided to call for critical presentations of practice, which would address one or more of the following areas:

- embedding ESD/GC in the ITE curriculum through subjects, thematic work, whole course development;

- partnerships between ITE institutions and NGOs, schools and other educational organizations;

- whole school approaches to ESD/GC;

- global linking.

Presenters were also asked to raise critical reflections in relation to the initiative described and situate the initiative in political and theoretical contexts. Presentations were uploaded onto the Network website and online conference proceedings published.

Feedback through evaluation comments was analysed and discussed by the Steering group. This analysis combined with participant suggestions for future conferences led to the proposal of the following themes for the 2009 conference:

- perspectives on $\mathrm{ESD} / \mathrm{GC}$ : thoughts, challenges and tensions;

- researching the impact of ESD/GC ITE provision on beginning teachers;

- developing criticality through practice.

Both keynote presentations were concerned with criticality. Räsänen (2010) from Oulu University addressed developing criticality in new teachers, and Shah (2010) examined what criticality in ESD/GC means in policy and practice. During the Plenary, a panel of key policy makers from Scotland, Northern Ireland, Wales and England discussed what constitutes critical thinking in $\mathrm{ESD} / \mathrm{GC}$ in beginner teachers.

The 2010 conference was entitled 'Education of Hope: The Impact of ESD/GC on the Well-being of Teachers and Young People'. The following questions were posed in the guidance for the 2010 conference in order to explore and develop the theme of well-being and $\mathrm{ESD} / \mathrm{GC}$ :

- Does ESD/GC provide hope or despair? Do we have to go through despair to get to hope?

- What do we mean by well-being? What impact does ESD/GC have on the well-being of beginner teachers and on young people? How can we evidence that impact? 
- How can we develop a curriculum content and pedagogy that helps new teachers acquire the attributes they need to enable young people to 'make a difference'? How can we mainstream this practice?

The Keynote address 'The Long Transition: Educating for Optimism and Hope in Troubled Times' given by Hicks (2010) set the context for the day. At each conference, there are opportunities for network, both formally and informally.

\section{The Network website}

To further support the learning community of practice all the outcomes from the conference are published online on the Network website (www.lsbu.ac.uk/ccci). This is supported by the publication of conference proceedings in hard copy so that the Network has a presence in libraries as well as providing the presenters with a more public audience for their papers. The website was launched initially on the Centre for Cross Curricula Initiatives site and soon moved to a linked independent site. Contacts, events and activities with examples of practice and policies are provided for each country. Academic articles and downloadable teaching resources are also available on the site.

\section{Conclusion}

At the launch in 2007, the Network had two aims: (1) to develop a UK wide community of practice in ESD/GC and Teacher Education (TE) through which good practice can be shared and disseminated and (2) to contribute to embedding $\mathrm{ESD} / \mathrm{GC}$ in UK TE institutions. The researchers are confident that the primary aims are being fulfilled as there is now a vibrant UK wide teacher education community of practice in ESD/GC whereby radical practice can be explored, questioned and shared. The rapidly changing and somewhat depressing government policy context for education particularly in England makes it difficult to predict how effectively the Network can affect policy change and/or long lasting change in course content so as to embed ESD/GC in teacher education across the UK. The potential demise or scaling down of the subject centres of the Higher Education Academy will undoubtedly affect the substantial support that the Network currently receives from ESCalate as the subject centre for education. At the current time we are not clear what will happen to the Training and Development Agency, but it is highly likely that it will no longer be able to provide the support for the network that it has done in the past. However, new alliances and networks to defend and argue for ESD/GC in the curriculum are springing up. The Network will work alongside new and existing alliances to try to convince policy makers of the critical need to ensure that new teachers are equipped to develop effective $\mathrm{ESD} / \mathrm{GC}$ in schools.

Whatever the challenges ahead we are confident that the Network is now strong enough to develop strategies to ensure that ESD/GC not only survives but further develops in this changing context. The title of our 2011 conference 'Building Capacity for ESD/GC in Times of Change' seems very appropriate for the next stage of our journey. We need to 
retain our optimism and hope and remember the words of Friere (1994, as cited in Hicks, 2010).

One of the tasks of the progressive educator is to unveil opportunities for hope, no matter what the obstacles might be.

\section{References:}

Bennell, S. (2008). Policy and developments in ITE in Wales. Retrieved January 23, 2011, from http://www.lsbu.ac.uk/ccci/uk_ite_network/presentations.shtml

Dalmau, M. C., \& Gudjonsdottir, H. (2002). Framing professional discourses with teachers in Loughran. In J. T. Russell (Ed.), Improving teacher education practice through self study (pp. 109-112). London: Routledge.

Friere, P. (1994). A pedagogy of hope. London: Continuum.

General Teaching Council for Northern Ireland. (2006). Teaching: The reflective profession. Belfast: GTCNI.

Hicks, D. (2010). The long transition: Educating for optimism and hope in troubled times. Retrieved November 4, 2010, from http://www.lsbu.ac.uk/ccci/uk_ite_network/docs/hi cks10\%20The\%20Long\%20Transition.pdf

Mc Quaid, N. (2008). Global dimension in schools in Northern Ireland. Retrieved September 5, 2010, from http://www.1sbu.ac.uk/ccci/uk_ite_network/presentations.sht $\mathrm{ml}$

Räsänen, R. (2010). Developing critical global citizenship and education for sustainable development in teacher education. In S. Inman \& M. Rogers (Eds.), Developing critical global citizenship and education for sustainable development in teacher education (pp. 5-20). The UK Teacher Education Network for Education Sustainable Development/Global Citizenship July 2009 Conference Proceedings. London: CCCI.

Shah, H., \& Brown, K. (2010). Developing critical global citizenship and education for sustainable development in teacher education. In S. Inman \& M. Rogers (Eds.), Developing critical global citizenship and education for sustainable development in teacher education. The UK Teacher Education Network for Education Sustainable Development/Global Citizenship July 2009 Conference Proceedings (pp. 21-26). London: CCCI.

Training and Development Agency. (2007). Professional standards for qualified teacher status and requirements for initial teacher training. London: London Training and Development Agency.

UNESCO. (2005). Promotion of a global Partnership for the UN Decade of Education for Sustainable Development. Retrieved December 10, 2010, from http://unesdoc. unesco.org/images/0014/001473/147361e.pdf

Wenger, E. (2006). Communities of practice in and across 21 st century organizations. Retrieved March 3, 2010, from http://www.ewenger.com/theory/communities_of_prac tice_intro.htm 
Wisely, T., Barr, I. M., Britton, A., \& King, B. (2010). Education in a global space Research and practice in initial teacher education. Edinburgh: IDEAS/UK Aid.

\section{Correspondence:}

Professor Sally Inman, Head of Centre for Educational Research and Director CCCI, Department of Education, London South Bank University, 103 Borough Road, London SE10AA, 02078158125. Email: inmansj@lsbu.ac.uk 